\title{
Conducting a Case Study in Supply Management
}

\author{
Anni-Kaisa Kähkönen \\ Lappeenranta University of Technology, School of Business \\ P.O. Box 20, FI 53851 Lappeenranta, Finland \\ Email: anni-kaisa.kahkonen@lut.fi
}

\begin{abstract}
The aim of this article is to enhance the understanding about case studies as one of the research methods used in qualitative research especially in the research field of supply management. By using an example case study this article illustrates how a case study can be conducted successfully and how the validity and reliability of the research should be evaluated. The study shows that a case study as a research method is suitable for the research of supply chain management and purchasing and supply management. Because case study enables the collection of rich and profound data, an in-depth analysis of the phenomenon in question can be reached which can be highly critical for example in the development of supply relationships. The article has practical relevance especially for academic researchers in the fields of supply chain management, logistics, supply management and operations management by offering initial insights into the importance of the research process in case studies. Case studies have been criticized for the lack of rigor and thus it is important to highlight the significance of the accuracy and systematic way of action in the case research.
\end{abstract}

Keywords: qualitative research, case study, interview, data analysis

\section{Introduction}

Case study is one of the research strategies that can be chosen when conducting a qualitative research. Case studies have been criticized for the lack of rigor (Ellram, 1996) and for having a soft nature especially when compared with quantitative research with statistical methods. However, many researchers argue that both qualitative and quantitative methods are needed in order to ensure the diversity and profundity of the academic research. Qualitative and quantitative research may aim at different objectives and for example case research does not purport to produce findings that can be generalized in a statistical sense, but as Yin (2003) suggests, the findings will be valuable in an analytical sense if they clarify or extend understanding of the existing theory. According to Miles and Huberman (1994), flexibility, richness, holism, causality assessment, the possibility of locating meanings and the natural setting are some of the advantages of qualitative research. McCutcheon and Meredith (1993) have argued that case studies can be seen as a particularly useful when assessing "real world" examples and Ellram (1996) continues that case studies are excellent in providing detailed explanations of "best practices".

Seuring (2008) states that the use of case studies would be particularly suitable for approaching several stages of a supply chain because they allow direct observation of the field. In addition to Seuring (2008), several authors have found case studies useful and valuable in the research made in the fields of supply chain management, logistics, operations management, and purchasing and supply management. According to Halinen and Törnroos (2005) and Järvensivu and Törnroos (2010), a case 
strategy is the most suitable for studying business networks. Voss, Tsikriktsis and Frohlich (2002) argue that case research has consistently been one of the most powerful research methods in the research made in the field of operations management. Ellram (1996) states that excellent opportunities exist for using case study research methodology in many areas of logistics and purchasing.

The aim of this article is to describe how a case study can be conducted successfully and how the research process should proceed. The description of the research process is based on a literature review on case method and on an extensive case study conducted in the research field of supply management by the author. The topic of this example case study was a supply network containing various buyer-supplier relationships.

\section{How to Conduct a Case Study?}

This section gives an overview of how a case study can be conducted and how the research process develops during the research. In this article, the research process for case studies is presented through eight different phases. Figure 1 shows the eight phases for case research based on the literature review of previous studies on case method and the research process conducted in the example case study by the author.

Figure 1. The research process for case studies

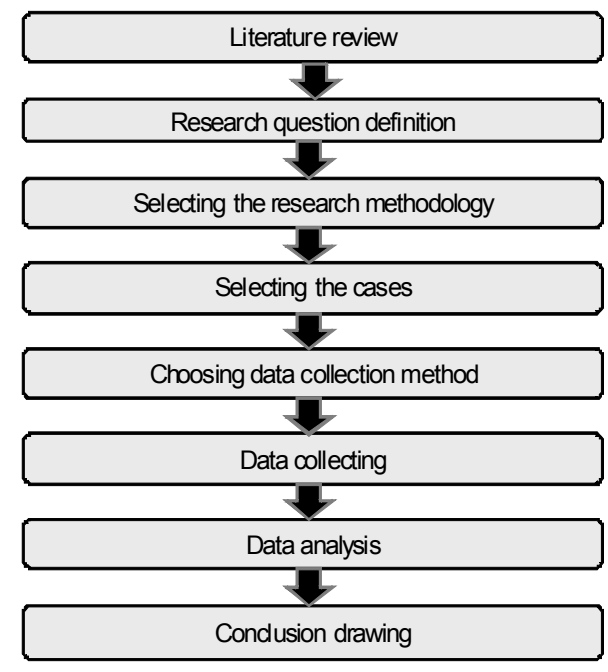

As Figure 1 shows, the first phase of the research process is the literature review which is the beginning of the research. As Stuart et al. (2002, p. 423) state, "all research starts from an examination of existing theory", and thus the process should always start with an extensive literature review which gives a preunderstanding of the research topic. A literature review creates the basis for the research and it enables researcher to identify possible research gaps which moreover, defines the research questions and research strategy used.

\subsection{Choosing the research strategy}

The choice of methodology and data collection method should be based on the research questions (Stuart et al., 2002). Yin (2003) has argued that defining the research questions is probably the most important step to be taken in a research. The aims and objectives of a research are defined in the form of research questions. The researcher needs to be aware of the substance (what is the study about) and form (what kind of question is asked, i.e. "who", "what", "where", "why" or "how") of the questions (Yin, 2003). Koulikoff-Souviron and Harrison (2005) have stated that for example in the research of supply chains, the questions can be asked at different levels of analysis depending on the scope of the study. Harland (1996) has further determined that in the research of purchasing and supply management these levels are the internal chain, the dyadic relationship, the external chain, and the network. According to Voss et al. (2002), research questions may evolve over time and the constructs may be modified, developed or abandoned. This is a potential strength because it allows the acquisition of more knowledge than if the questions were fixed. Yin (2003) has defined that because "how" and "why" questions are explanatory in nature, they are likely to lead to the use of case studies.

Yin (2003) defines a case study as an empirical inquiry that investigates a contemporary phenomenon within its real-life context, when the boundaries between the phenomenon and the context are not evident and multiple sources of evidence are used. The different aspects of the case are understood in relation to one another as a coherent whole or configuration, rather than as modular assemblages of variables (Dubois \& Araujo, 2007). According to Eisenhardt (1989, p. 534), “a case 
study is a research strategy which focuses on understanding the dynamics present within single settings." Case study allows investigation of a contemporary phenomenon that is difficult to separate from its context, and necessary to study within it in order to understand the dynamics in the setting (Halinen \& Törnroos, 2005).

Moreover, the fact that a case study combined with interviewing allows more in-depth discussion in which why and how questions can be asked and the fundamental reasons behind and the background nature of the issues can be explained further justifies the choice of method in several studies. Case design makes it possible to gather rich empirical data and thereby to gain a deep understanding of the phenomenon in question.

As Table 1 shows, case studies may be exploratory, explanatory or descriptive (see Yin, 2003). The aim in an exploratory case study is to define questions and hypotheses for a subsequent study, or to determine the feasibility of the desired research procedure. A descriptive case study gives a complete description of the phenomenon within its context, whereas an explanatory case study comprises data based on cause-effect relationships, explaining how events happened (see also Seuring, 2008).

\subsection{Case selection}

After defining the research questions and choosing the research strategy, a suitable sample for the study can be selected. In the case study, the selection of the case and case companies as well as the number of cases, units of analysis and the time perspective for the research are in highly critical role. In the example case study from the research field of supply management, four case companies were selected to be the case companies of the study. They were selected because i) they represented different nodes of the network in question and hence had different roles in it, ii) there were different kinds of relationships between them, iii) they were all significant actors in the industry in question, and iv) analyzing them would produce a comprehensive picture of the network. Furthermore, the fact that they had different roles, power positions and relationships in the network was relevant to the research aim of the study, and supported the selection of case companies. There were four different buyer-supplier relationships between these case companies and these relationships were used as units of analysis in the example case.

Yin (2003) suggests four types of design for case studies: single or multiple cases examined from the holistic perspective with single units of analysis on the one hand, and from an embedded perspective with multiple units of analysis on the other (see Figure 2). In the example case study, the case under the investigation was a supply network containing four different buyer-supplier relationships. Thus, it was defined that the case study was an embedded single case study. Because the main issue of the research was a network and because there was only one network that was studied, the case was clearly a single case. However, the network contained four different buyer-supplier relationships which were the units of analysis in the study. Thus, there were multiple units of analysis and the perspective could be defined to be an embedded one. For example, Dubois and Araujo (2007) suggest that the use of multiple units of analysis strengthens the study. This case situation is illustrated in Figure 2 as an embedded single-case design.

Table 1. Three types of case studies

\begin{tabular}{|c|l|l|l|}
\hline & \multicolumn{1}{|c|}{ Exploratory } & \multicolumn{1}{c|}{ Explanatory } & \multicolumn{1}{c|}{ Descriptive } \\
\hline Aim & $\begin{array}{l}\text { To define questions and hypotheses } \\
\text { for a subsequent study, or to determine } \\
\text { the feasibility of the desired research } \\
\text { procedure }\end{array}$ & $\begin{array}{l}\text { To explain how events happened by } \\
\text { comprising data based on cause- } \\
\text { effect relationships }\end{array}$ & $\begin{array}{l}\text { To present a complete description of } \\
\text { the phenomenon within its context }\end{array}$ \\
\hline Questions & How, Why & How, Why & Who, What, Where \\
\hline Example case studies & $\begin{array}{l}\text { Miemczyk (2008), Peck (2005), } \\
\text { Seuring (2003) }\end{array}$ & Elango (2008), Soroor et al. (2009) & $\begin{array}{l}\text { Kähkönen and Lintukangas (2010), } \\
\text { Murray et al. (2008) }\end{array}$ \\
\hline
\end{tabular}


Figure 2. Four types of case design

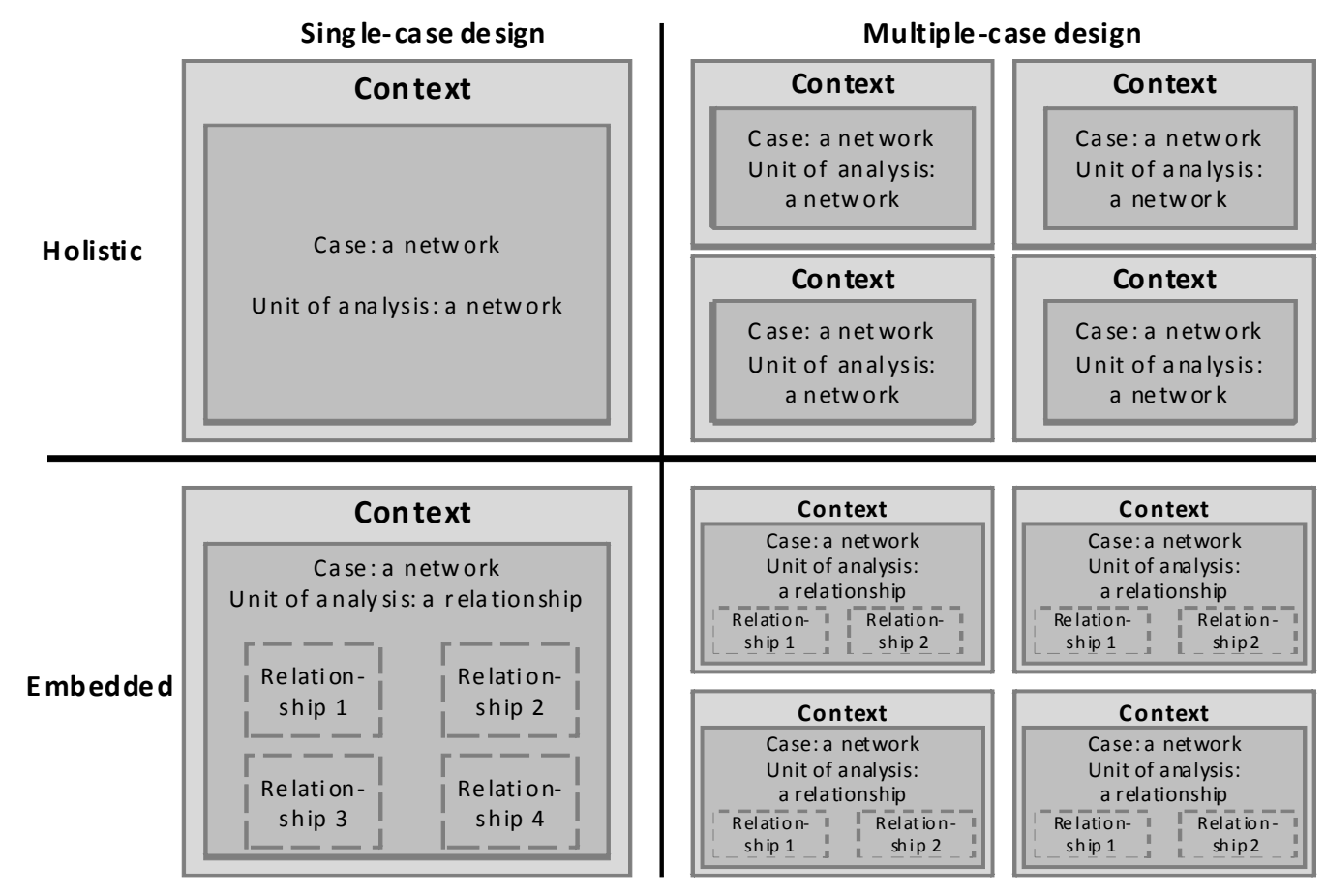

However, if the researcher would have selected that the research phenomenon under the investigation should be only a supply network and used the whole network, not the relationship, as a unit of analysis, then the situation of the example case would have been single case with holistic perspective (see Figure 2). In the situation with several networks, the case design would have been a multiple case with a holistic or embedded perspective depending on the units of analysis (network or relationship as a unit of analysis).

In addition to the number of cases and the number of units of analysis, the time perspective for the case study needs to be determined. For example, Halinen and Törnroos (2005) have defined that the problem of time is central in network research. Voss et al. (2002) have made a distinction between retrospective and current cases, and further separated the historical or long-time period studies to retrospective and longitudinal cases. Table 2 shows the characteristics of single and multiple cases, and retrospective and longitudinal cases based on the literature review and table presented earlier in Voss et al. (2002). Because different choices lead to different advantages and limits, the researcher should always be able to justify and explain why certain decisions and selections have been made. Equally important is the rationale behind the selection of the data collection method and key informants.

\subsection{Data collection}

Yin (2003) suggests that multiple sources of evidence should be used to establish construct validity and reliability of the study. According to Dubois and Araujo (2007), the use of multiple respondents makes it possible to capture a variety of perceptions and meanings, which is vital to the understanding of complex business relationships. Furthermore, having numerous and highly knowledgeable informants who view the focal phenomena from diverse perspectives should limit interview bias (Eisenhardt \& Graebner, 2007). Therefore, several research informants and data from different sources (data triangulation) should be used in the case studies in order to limit biases.

It is common that the data for a case study is collected through interviews (see Yin, 2003). According to Eisenhardt and Graebner (2007), the 
Table 2. Choosing the number and type of cases (modified from Voss et al., 2002)

\begin{tabular}{|c|c|c|c|c|}
\hline & Single cases & Multiple cases & Retrospective cases & Longitudinal cases \\
\hline Typical & One case & Several cases & Study of the past & Two or more points in time \\
\hline When to use & $\begin{array}{l}\text { When the case: } \\
\text { - is a critical case to test a } \\
\text { well-formulated theory } \\
\text { - is an extreme or unique } \\
\text { - reveals a previously } \\
\text { inaccessible phenomenon }\end{array}$ & $\begin{array}{l}\text { When the aim is to develop a } \\
\text { rich, theoretical framework } \\
\text { by replication } \\
\text { - predict similar or to show } \\
\text { contracting results among } \\
\text { replications }\end{array}$ & $\begin{array}{l}\text { When the aim is to look } \\
\text { backwards }\end{array}$ & $\begin{array}{l}\text { When the aim is to define how } \\
\text { certain conditions change over } \\
\text { time }\end{array}$ \\
\hline Advantages & $\begin{array}{l}\text { Depth of the study } \\
\text { - Can richly describe the } \\
\text { existence of a phenomenon }\end{array}$ & $\begin{array}{l}\text { - Augment external validity } \\
\text { - Smaller observer bias } \\
\text { - Allow case comparisons } \\
\text { - Provide a stronger base for } \\
\text { theory building }\end{array}$ & $\begin{array}{l}\text { - Allow collection of data on } \\
\text { historical events } \\
\text { - Overcome the problems of } \\
\text { retrospective cases }\end{array}$ & $\begin{array}{l}\text { - Overcome the problems of } \\
\text { retrospective cases }\end{array}$ \\
\hline Limits & $\begin{array}{l}\text { - Generalizability } \\
\text { - The risk of misjudging the } \\
\text { representativeness } \\
\text { - The risk of exaggerating } \\
\text { easily available data }\end{array}$ & $\begin{array}{l}\text { - Less depth per case } \\
\text { - May require extensive } \\
\text { resources and time }\end{array}$ & $\begin{array}{l}\text { - Difficult to determine } \\
\text { cause and effect } \\
\text { - Participants may not recall } \\
\text { important events }\end{array}$ & $\begin{array}{l}\text { - May be difficult to do } \\
\text { because of long time } \\
\text { period }\end{array}$ \\
\hline
\end{tabular}

interview is a highly efficient way of gathering rich, empirical data. Interview as a data collection method was used also in the example case study. Because of the research aims and questions of the example case study, it was significant to collect rich and profound data, and thus the interview as a data collection method was seen to be the most suitable one.

Given the approach of the example case study, the questions concerned issues on the organizational (i.e. how the organization works) rather than the individual (i.e. individual behaviour) level (see Yin, 2003). Yin (2003) and Hirschman (1986) have recommended that theory should be used in case studies and for example interview questions should be formed on the basis of the existing theory. The questions in the example study were based on the literature review and existing theory and they covered both the supply management perspective and the perspective of marketing because both the buyer and supplier from each relationship need to be interviewed.

The interview questions were validated in a review process involving several researchers (researchers of a certain research project) who checked and modified the questions. They were then tested on a few key informants in the case companies, and the ones in which problems arose were modified. If possible, the wording and the order of the questions remained unchanged for all respondents. The interviewees were nevertheless allowed to talk freely, and the questions were adjusted accordingly with due consideration to the informant's role and position in the company. Questions concerning purchasing and supply were used mainly when the informant represented the supply side, and those covering information sharing and market knowledge were asked of informants representing marketing and sales.

The participation of six interviewers in the data collection process facilitated investigator triangulation. According to Eisenhardt (1989), the use of multiple investigators has two key advantages: it enhances the creative potential of the study because researchers often have complementary insights that add to the richness of the data, and it increases confidence in the findings of the convergence of observations. The use of multiple researchers was beneficial not only in the data collection process but also in the data analysis: the researchers discussed the interpretations and findings, for example, and hence brought to light different perspectives and observations.

In the example case 29 interviews were conducted with the case companies' personnel, of which 27 were face-to-face, semi-structured interviews. The other two were email-based 
Table 3. Interviews in the example case companies

\begin{tabular}{|l|c|c|c|c|}
\hline $\begin{array}{c}\text { Case } \\
\text { company }\end{array}$ & $\begin{array}{c}\text { Number of } \\
\text { interviews }\end{array}$ & $\begin{array}{c}\text { Number of } \\
\text { interviews }\end{array}$ & $\begin{array}{c}\text { Number of } \\
\text { interviewees }\end{array}$ & $\begin{array}{c}\text { Company's } \\
\text { role in the } \\
\text { network }\end{array}$ \\
\hline Company A & 16 & 7 & 3 & Buyer, Supplier \\
Company B & 6 & 4 & 2 & Buyer \\
Company C & 5 & 1 & 2 & Supplier \\
Company D & 2 & 1 & 1 & Supplier \\
\hline Total & $\mathbf{2 9}$ & $\mathbf{1 3}$ & & \\
\hline
\end{tabular}

interviews, the structured interview form being emailed to the interviewees and the questions focusing on the volumes of sales and purchases between the case companies. This information was collected in written form in order to ensure accuracy of the numerical data and to minimize the possibility of researcher misperception. Table 3 shows the numbers of interviews and interviewees in each case company of the example case, the number of relationships (from the case network) in which the company was involved, and its role in the network and in the relationships.

As the table shows, there were 16 interviews in Company A, six in Company B, five in Company C, and two in Company D. Company A was the focal company of this network and was involved in three relationships. It also represented both the buyer and the supplier side, which is why more interviews were carried out there. Given that Company B and Company $\mathrm{C}$ were both involved in two relationships and Company D only in one, the point at which new interviews did not provide new evidence (saturation point) was reached earlier in Company $\mathrm{D}$ than in the other case companies. In fact, the saturation point was used in determining the sufficiency of interviews. This is characteristic of case studies, and as Eisenhardt (1989) states, data saturation occurs when corroborating the existing interview data with more interviews would not bring any new information relevant to the research questions.

The research informants were selected and interviewed on the basis of their active involvement in buyer-supplier relationships, supply management and marketing. The interviewees from the buyer companies mostly represented purchasing and supply management (i.e. purchasing directors, supply managers), whereas those in marketing and selling (i.e. customer directors, sales managers) represented companies in the supplier role. In order to obtain additional information and complementary perspectives interviews were also conducted with informants from other company levels and in other positions (i.e. CEOs, commercial directors, quality managers). Given that Company A was the focal company in the case network and was in the role of both buyer and supplier, and in order to cover both perspectives, interviews were conducted with the purchasing director and supply manager, as well as with the customer director, for example.

Given the focus of the example case study on buyer-supplier relationships, the interviews covered both the buyer and the supplier side. Take the case of the relationship between Company $D$ and Company A, for example. One interviewee represented sales and marketing management in Company D, which was in the role of supplier in this relationship, and another represented supply management in Company A because of its buyer role. Company A also represented the viewpoint of sales and marketing because it was in the supplier role in its relationship with Company $B$, whereas the interviewees from Company B represented the supply side. It was considered necessary to interview both sides from each relationship. This yielded interesting results on account of the different reactions in the companies to the same issue depending on the role they had.

The study also incorporated data triangulation in the use not only of several informants but also of various types of data. The sources of the empirical data included: i) interview data, ii) data on sales and purchases, iii) company information taken from a database, iv) the case companies' annual reports, v) market information, and vi) reports and studies concerning the business of the case industry worldwide.

According to Eisenhardt (1989), case study data may be qualitative, quantitative or both. As Tesch (1992, p. 55) posits, "qualitative data is any information the researcher gathers that is not expressed in numbers", whereas in the view of Miles and Huberman (1994, p. 1) qualitative data is "a source of well-grounded, rich descriptions and explanations of processes in identifiable local contexts." Both qualitative and quantitative data were utilized in the example case study, and as 
suggested by earlier studies, quantitative data was used for validation purposes. The numerical quantitative data was gathered from a database that provides company information, including basic information about the case companies (turnover and numbers of employees, etc.), and other financial information. Numerical data on sales and purchases was collected directly from the case companies by means of email-based interviews. This and the interview data comprised the primary data of the study. The secondary data comprised the database information as well as all other material mentioned above.

\subsection{Data analysis}

Miles and Huberman (1994) and Griggs (1987) suggest that data reduction, data display, and conclusion drawing and verification can be used as data-analysis techniques in the case research. In fact, one of the most critical phases in the process of case research, is the analysis of the data. After the data is collected, the researcher should be aware of data analysis techniques. However, in many academic articles this critical phase is often discussed in too general terms. Thus, next this article illustrates how the process of data analysis was conducted in the example case study and how it can be reported in academic writings.

In the example case, all the interviews, except the two that were email-based, were audio-recorded, and notes were taken during them. The recordings were transcribed literally, and non-verbal occurrences such as laughter and long breaks were also indicated. The transcriptions produced 375 pages of data, 14 pages per interview. The two email-based interviews produced seven pages of data. After the interviews were transcribed literally, the resulting qualitative data was read several times and notes were taken and precoding was done. The pre-coding of the data was based on the interview themes. This was done by using colour-coding and other notes in the transcriptions.

Reading and re-reading the data helped to familiarize the researcher with it and started the process of structuring and organizing the data into meaningful units. This process heightens the researcher's awareness of the patterns, themes and categories of meaning embedded in the data (Shaw, 1999). After reading the data thoughtfully, the data was colour-coded based on the interview themes. As Griggs (1987) suggests, abbreviations as codes were also used and marked in the margins of the transcripts.

The pre-coding provided the basis for the final coding. This followed the interview themes because it seemed to be a logical, systematic and reliable way of doing, it and secured the chain of evidence. The coding was done manually, and it was checked several times afterwards. Codes were used to bring order, structure and meaning to the raw data (see Shaw, 1999; Strauss \& Corbin, 1998). Colour-coding, involving the allocation of a colour to each topic or theme, was used, and a total of 11 themes were identified.

The coding provided a basis for the classification of the data, which was categorized by themes. According to Dey (1993), categorization causes the data to lose its original shape following its division into relevant blocks for analysis. Nevertheless, it facilitates more effective comparison. As Strauss and Corbin (1998) state, comparison has an important role in data analysis because it allows identification of variations in the patterns found. This process also represents a method of data reduction and provides an initial level of analysis (Miles \& Huberman, 1994; Tesch, 1992). According to Miles and Huberman (1994, p. 10), data reduction refers to "the process of selecting, focusing, simplifying, abstracting, and transforming the data" and, as Griggs (1987, p. 20) adds, "should not be confused with throwing away or ignoring data." Data display, on the other hand, refers to the use of quotations, tables and matrices, for instance (Griggs, 1987).

In the example case, the coded and categorized data was subjected to qualitative content analysis. According to Tesch (1992), the units in content analysis may be words, sentences, paragraphs or themes (see also Neuendorf, 2002). In this case they were sentences: a word was considered too narrow because the aim was to analyze the meanings qualitatively rather than to separate words from larger entities. Paragraphs also formed units of analysis because sometimes the meanings and the interviewee's key thoughts required more than one sentence to be fully understood.

According to Yin (2003), the reliability of a study can be increased through the use of a case study protocol, developing a database and ensuring the chain of evidence and this advice was followed in the 
example case. The creation of a case study database facilitated the organization of the qualitative data and the maintenance of a chain of evidence. The coded and categorized data were put in separate documents in order to make the analysis easier. However, the original file containing all the interview data was preserved. The case study database comprised all this data, i.e. the original transcriptions, the coded and categorized data, the data from the email-based interviews as well as the summaries, memos, matrices and mind maps.

The data was scrutinized separately in accordance with the main theoretical constructs. However, the same data was used in several documents in order to confirm the relationships between the constructs. Mind maps also helped in identifying and analyzing the relations between the different constructs and themes, and in highlighting the relations between the case companies. This phase helped in creating a deeper understanding of the big picture. The dataanalysis phase produced several summaries, mind maps, matrices and memos. The interview data was compared and complemented with the other empirical (secondary) data. Finally, all the data was considered in the light of the theoretical insights and interfaces were sought. This involved going back to the literature review and collecting complementary material in order to find support for the empirical results or to explain them. Tables and summaries were used in comparing the empirical data with the theoretical framework.

\section{Evaluating the Validity and Reliability of the Case Study}

\subsection{Validity of the case study}

One of the most important issues in research in general, is the evaluation of the validity and reliability of the study. According to Yin (2003), the quality of case research depends on the construct validity, internal validity, external validity and reliability of the research design. Stuart et al. (2002) suggest that the most important ones for the case study are construct validity and internal validity. It has to be noted that validity and reliability are considered from different standpoints in qualitative and quantitative research. Given the qualitative nature of the example case study, the validity and reliability of the study were considered from the perspective of qualitative research. Therefore, the definitions of Yin (2003) for example were approved and followed.

Voss et al. (2002) refer to construct validity as the extent to which the correct operational measures of the studied concepts are established. According to Yin (2003) and Stuart et al. (2002), construct validity can be ensured through the use of multiple sources of evidence, establishing a chain of evidence and asking key informants to review case study reports (see also Beverland \& Lindgreen, 2010). Multiple sources of evidence (data triangulation) were used in order to strengthen the construct validity of the example study. First, a variety of informants were interviewed. Secondly, data was obtained from several sources. Investigator triangulation was evident in that six researchers were involved in the interview and dataanalysis processes. Furthermore, the chain of evidence strengthened the construct validity of the study: the steps of the research were well documented, and all the original evidence is available and carefully documented. As Seuring (2008) notes, even if the case study is often criticized for its lack of rigor (see also Ellram, 1996), case study research will continue to allow in-depth analysis of contemporary phenomena if the research process is carried out in a structured way and is well documented.

As suggested for example by Jauch, Osborn and Martin (1980), the interviewees of the example case reviewed the case reports and the results were presented to the informants in an attempt to prevent interview bias. It was highly critical that the interviewees were able to comment on possible researcher misperceptions but they could not change the results in their favour. Miles and Huberman (1994) recommended reviewing the results and interpretations with informants, but nevertheless retaining them in their original form. Furthermore, according to Yin (2003) this process enhances construct validity, and according to Hirschman (1986) this can be used to determine the credibility of the study.

Yin (2003) defines external validity as the domain in which a study's findings can be generalized, in other words how accurately the results represent the studied phenomenon (see Ellram, 1996). Neuendorf (2002) determines generalizability as the extent to which the findings may be applied to other cases. 
According to Stuart et al. (2002), one of the most serious charges against case research is that the samples are too small to allow generalization of the results, and that this criticism stems from confusion between two types of generalization - statistical generalization on which survey research relies and analytical generalization on which case studies rely. According to Stuart et al. (2002, p. 430), "with case research, generalization is from each case to broader theory not from samples to populations." The aim of the example case study was at analytical generalization, and in terms of external validity the recommendations of Yin (2003) were followed. Yin (2003) also recommends increasing external validity through the use of theory in single-case studies, and thus the coding and analysis of the empirical data should be theory-based (see also Hirschman, 1986).

According to Yin (2003, p. 34), "internal validity refers to establishing a causal relationship, whereby certain conditions are shown to lead to other conditions, as distinguished from spurious relationships", and further that it is only a concern in causal or explanatory case studies and is irrelevant in descriptive and exploratory studies. Hence, given that the example case study was mainly descriptive in nature, internal validity was not considered to be as important as other forms of validity. However, according to Stuart et al. (2002), with regard to a single case, pattern matching ensures the matching of the data patterns with the proposed patterns, thereby providing good evidence for a given proposition and increasing internal validity. Account was therefore taken of internal validity, and discussions with key informants helped in ensuring that a particular result was attributable to a particular phenomenon. In other words the reasons behind the issues were discussed, which was considered necessary given that the main research question was a "how" question.

\subsection{Reliability of the case study}

In addition to the validity of the study, reliability is another evaluation criterion for judging research quality. According to Yin (2003), the reliability of a study reflects the extent to which its operations can be repeated and yield the same results. Näslund (2002) refers to the common definition of qualitative research as more subjective than quantitative research, which is consequently more objective (see also Morgan \&
Smircich, 1980). This often refers to the role of the researcher. Hirschman (1986) highlights the meaning of confirmability, suggesting that outside auditors should be used to judge whether or not the interpretations are drawn in a logical and unprejudiced manner. Yin (2003) also mentions the utilization of several researchers in the context of study bias: in order to test for bias and the tolerance of contrary findings the preliminary findings should be reported to two or three critical colleagues, who in turn should offer alternative explanations. In the example case study several researchers read and commented on the case reports. The research team also discussed the interpretations and the findings, and the results were also discussed with the case companies. As Yin $(2003$, p. 37) states, "The goal of reliability is to minimize the errors and biases in a study."

Again according to Yin (2003), using a case study protocol and developing a case study database could increase the reliability of the study (see also Beverland \& Lindgreen, 2010): these recommendations were followed in the example case study. According to Ellram (1996, p. 104), "a case study protocol includes the interview guide, as well as the procedures to be followed in using the test instrument." As mentioned above, a case study database was created: the evidence obtained, the stages of the research process and the interview questions and procedures were all carefully documented, thereby increasing the reliability.

\section{Conclusions}

Despite the criticism towards case research, several researchers have found it interesting and useful to conduct a case study in order to analyze a certain research topic. This article as well as many others argue that if a case study is conducted in a proper way and the instructions given in previous literature are followed, important and interesting research results can be found and there is no need to aim at statistical generalization but the analytical generalization is as valid as the statistical one.

By using an example case study from the research field of supply management, this article has demonstrated how a case study can be conducted and how the validity and reliability of the case study can be evaluated. Based on the literature review made and the research process of the example case 
study a framework of the case study process was created. This framework was presented in Figure 1 and it described the process of case studies in detail. The process starts from the literature review and through eight different phases the final goal is the conclusion drawing (see Figure 1).

This article enhances the understanding concerning the process of case studies and highlights the significance of qualitative case studies in especially in the research fields of supply chain management, logistics, purchasing and supply management and operations management. In many cases the research topic in these fields requires the presence of "how" questions. Because rich and profound data can be collected through a case study and interviews, the case study as a research method facilitates the in-depth analysis of the phenomenon under investigation. Moreover, this can be highly critical in these research areas and for example in the development of supply relationships, chains and networks.

\section{References}

Beverland, M., and Lindgreen, A. (2010). What makes a good case study? A positivist review of qualitative case research published in Industrial Marketing Management, 1971-2006. Industrial Marketing Management 39 (1), pp. $56-63$.

Dey, I. (1993), Qualitative data analysis - A user-friendly guide for social scientists, Routledge, London.

Dubois, A., and Araujo, L. (2007). Case research in purchasing and supply management: Opportunities and challenges. Journal of Purchasing E Supply Management 13 (3), pp. $170-181$.

Eisenhardt, K.M. (1989). Building theories from case study research. Academy of Management. The Academy of Management Review 14 (4), pp. 532 - 550.

Eisenhardt, K.M., and Graebner, M.E. (2007). Theory building from cases: Opportunities and challenges. Academy of Management Journal 50 (1), pp. 25 - 32.

Elango, B. (2008). Using outsourcing for strategic competitiveness in small and medium-sized firms. Competitiveness Review: An International Business Journal 18 (4), pp. $322-332$

Ellram, L.M. (1996). The use of the case study method in logistics research. Journal of Business Logistics 17 (2), pp. $93-138$.

Griggs, S. (1987). Analysing qualitative data. Journal of the Market Research Society 29 (1), pp. 15 - 34.
Halinen, A., and Törnroos, J.-Å. (2005). Using case methods in the study of contemporary business networks. Journal of Business Research 58 (9), pp. 1285 - 1297.

Harland, C.M. (1996). Supply chain management: Relationships, chains and networks. British Journal of Management 7 (1), pp. $63-80$.

Hirschman, E. (1986). Humanistic inquiry in marketing research: Philosophy, method, and criteria. Journal of Marketing Research 23 (3), pp. $237-249$.

Jauch, L.R., Osborn, R.N., and Martin, T.N. (1980). Structured content analysis of cases: A complementary method for organizational research. Academy of Management. The Academy of Management Review 5 (4), pp. $517-525$.

Järvensivu, T., and Törnroos, J.- $\AA$. (2010). Case study research with moderate constructionism: Conceptualization and practical illustration. Industrial Marketing Management 39 (1), pp. 100 - 108.

Koulikoff-Souviron, M., and Harrison, A. (2005). Using case study methods in researching supply chains. In Research methodologies in supply chain management, H. Kotzab, S. Seuring, M. Müller, and G. Reiner (eds.), Physica-Verlag, Heidelberg, pp. $267-282$.

Kähkönen, A-K., and Lintukangas, K. (2010). Dyadic relationships and power within a supply network context. Operations and Supply Chain Management: An International Journal 3 (2), pp. $59-69$.

McCutcheon, D.M., and Meredith, J.R. (1993). Conducting case study research in operations management. Journal of Operations Management 11 (3), pp. 239 - 256.

Miemczyk, J. (2008). An exploration of institutional constraints on developing end-of-life product recovery capabilities. International Journal of Production Economics 115 (2), pp. $272-282$.

Miles, M.B., and Huberman, M.A. (1994), Qualitative data analysis - An expanded sourcebook, Sage Publications, Thousand Oaks, California.

Morgan, G., and Smircich, L. (1980). The case for qualitative research. Academy of Management Review 5 (4), pp. 491 500.

Murray, G.J., Rentell, P.G., and Geere, D. (2008). Procurement as a shared service in English local government. International Journal of Public Sector Management 21 (5), pp. 540 - 555.

Neuendorf, K.A. (2002), The content analysis guidebook, Sage Publications, Thousand Oaks, California.

Näslund, D. (2002). Logistics needs qualitative research Especially action research. International Journal of Physical Distribution \& Logistics Management 35 (5), pp. 321 - 338.

Peck, H. (2005). Drivers of supply chain vulnerability: an integrated framework. International Journal of Physical Distribution E Logistics Management 35 (4), pp. 210 - 232 
Seuring, S.A. (2008). Assessing the rigor of case study research in supply chain management. Supply Chain Management: An International Journal 13 (2), pp. 128 137.

Seuring, S.A. (2003). Outsourcing into service factories - An exploratory analysis of facility operators in the German chemical industry. International Journal of Operations $\mathcal{E}$ Production Management 23 (10), pp. 1207 - 1223

Shaw, E. (1999). A guide to the qualitative research process: Evidence from a small firm study. Qualitative Market Research 2 (2), pp. $59-70$.

Soroor, J., Tarokh, M.J., and Shemshadi, A. (2009). Theoretical and practical study of supply chain coordination. Journal of Business $\mathcal{E}$ Industrial Marketing 24 (2), pp. $131-142$
Strauss, A., and Corbin, J. (1998), Basics of qualitative research: Techniques and procedures for developing grounded theory, Sage publications, Thousand Oaks, California.

Stuart, I., McCutcheon, D., Handfield, R., McLachlin, R., and Samson, D. (2002). Effective case research in operations management: A process perspective. Journal of Operations Management 20 (5), pp. 419 - 433.

Tesch, R. (1992), Qualitative research: Analysis types and software tools, The Falmer Press, New York.

Voss, C., Tsikriktsis, N., and Frohlich, M. (2002). Case research in operations management. International Journal of Operations E Production Management 22 (2), pp. 195 219.

Yin, R.K. (2003), Case study research: Design and methods, Sage Publications, Thousand Oaks, California.

Anni-Kaisa Kähkönen, D.Sc (Econ. \& Bus.Adm.), is a researcher in Lappeenranta University of Technology, School of Business. Her current areas of interest include buyer-supplier collaboration, power relations, value nets and supply strategies, especially in the food industry. She is the corresponding author and can be contacted at: anni-kaisa.kahkonen@lut.fi 